\title{
IMPLEMENTATION OF EXTENDED CARDIOPULMONARY RESUSCITATION PROCEDURE IN IN-HOSPITAL CARDIAC ARREST: A PRELIMINARY SIMULATED STUDY
}

\author{
Maciej Sip ${ }^{1,2} \oplus_{0}$, Mateusz Puslecki ${ }^{1,2,3}{ }^{\infty}$, Marek Dabrowski ${ }^{2,4} \oplus^{\infty}$, Tomasz Klosiewicz ${ }^{1,2}{ }^{\infty}$, \\ Marcin Ligowski ${ }^{3}$, Sebastian Stefaniak ${ }^{3}$, Lukasz Szarpak ${ }^{5,6}{ }^{-0}$, Christopher Paprocki $^{2}$, \\ Marek Jemielity ${ }^{3}$, Bartlomiej Perek ${ }^{3}$ (i) \\ ${ }^{1}$ Poznan University of Medical Sciences, Department of Medical Rescue, Poznan, Poland \\ ${ }^{2}$ Polish Society of Medical Simulation, Slupca, Poland \\ ${ }^{3}$ Poznan University of Medical Sciences, Department of Cardiac Surgery and Transplantology, Poznan, Poland \\ ${ }^{4}$ Department of Medical Education, Poznan University of Medical Sciences, Poznan, Poland \\ ${ }^{5}$ Department of Emergency Medicine, Maria Sklodowska-Curie Medical Academy, Warsaw, Poland \\ ${ }^{6}$ Department of Emergency Medicine, Comprehensive Cancer Center in Bialystok, Poland
}

\section{ABSTRACT}

INTRODUCTION: The survival rate of patients after in-hospital cardiac arrest (IHCA) is poor. The implementation of novel technologies to conventional cardio-pulmonary resuscitation (CPR) may improve clinical outcomes.

AIM: To evaluate efficacy of extended CPR (ECPR) performed by physicians in the simulated scenario of IHCA.

MATERIAL AND METHODS: High-fidelity simulations were performed in a simulation room equipped with a full spectrum of emergency devices. Earlier, the physicians ( $n=60$, five courses) participated in a threeday training in the use of extracorporeal techniques. Eventually, 12 participants were divided into 4-member teams that were involved in three stages (assessed in terms of duration and quality) of scenario such as 1. Advanced Life Support (ALS) activities; 2. preparation of the extracorporeal membrane oxygenation device (ECMO); 3. cannulation and activation of ECMO.

RESULTS: All teams completed successfully scenario within recommended time of 60 minutes (ranged from $33 \mathrm{~min} .55 \mathrm{sec}$. to $37 \mathrm{~min}$.) after IHCA. In details, decision to activate ECMO team was taken between $8 \mathrm{~min}$. $45 \mathrm{sec}$. and $14 \mathrm{~min} .15 \mathrm{sec}$ of scenario, ECMO device prepared within $10 \mathrm{~min} .5 \mathrm{sec}$. to $15 \mathrm{~min} .30 \mathrm{sec}$. whereas peripheral vessels cannulated in $4 \mathrm{~min} .14 \mathrm{sec}$. to $6 \mathrm{~min}$. $10 \mathrm{sec}$. Of note, all evaluated times were the shortest for teams with decisive leaders.

CONCLUSIONS: Implementation of ECPR procedure is possible within recommended time after IHCA. It has also been shown that training with application of high-fidelity simulation techniques is of paramount importance in achievement and maintenance of ECPR skills, not only manual but also in effective communication.

KEY WORDS: in-hospital cardiac arrest, cardio-pulmonary resuscitation, extended cardio-pulmonary resuscitation, simulation, education

Disaster Emerg Med J 2021; 6(1): 10-20 


\section{INTRODUCTION}

Management of patients after in-hospital cardiac arrest episodes (IHCA) is still a real challenge for medical staff all over the world. For years, personnel have been attempting to reduce their frequency, implement effective therapy of sudden cardiac arrest (SCA) as well as appropriate resuscitation care. These actions are to ensure the highest possible survival rate for hospital discharge. The reported incidence of IHCA has ranged between 1 to $6 \mathrm{pa}$ tients per 1000 hospital admissions [1-3]. Generally, they are elderly people with many concomitant diseases who usually manifest symptoms at the time of hospital admission. The IHCA case analysis showed that the most common initial rhythm of SCA was asystole/PEA (79.3-84.3\%) but not VF/NT $(15.7-20.7 \%)[2,4]$. These results correlate strongly with a poor survival rate of about 10 to $20 \%$ of IHCA patients, where only half of them survived with good neurological outcomes [3-5]. Despite the enormous progress in medical technology, and although many detailed analyses have been carried out and standards of management and treatment of IHCA subjects have been changed, a poor progression has not changed markedly for many years. Only single reports noted slight increase in survival rate to $22.4 \%$, and decrease in the neurological disability index from $32.9 \%$ to $28.1 \%$ [4].

The development of technology and the implementation of procedures that complement the conventional techniques used in IHCA are aimed at improving survival. One of these is a sophisticated procedure of the extended cardio-pulmonary resuscitation (ECPR). It has been shown that ECPR, compared with the conventional $C P R$, increased coronary perfusion pressure, improved the effectiveness of defibrillation and the likelihood of return of spontaneous circulation (ROSC) $[6,7]$. This procedure requires a lot of commitment at every stage of its implementation, and the subsequent stages must be closely related to each other. At the time of SCA, it is important to continue additional activities from a preparation of the ECMO device at the beginning, cannulation and starting perfusion at the end [8-10].

While analyzing the cases of OHCA and IHCA in terms of ECPR procedure implementation, a number of discrepancies can be found. The mean age of OHCA patients is usually lower than that of IHCA subjects [11]. They are random ones with a poor medical history. It is important, but not always possible, to determine exactly the time of SCA iden- tification by witnesses of the event as well as CPR activities undertaken by them while assessing the potential no-flow time. On the other hand, IHCA patients are more likely to be burdened with comorbidities such as, lung diseases, hypertension, diabetes, chronic kidney disease, dyslipidemia and cancer. However, they are often monitored and stay in rooms with other patients, so early identification of SCA is more likely [10-12]. Thus, the time of providing assistance will be incomparably shorter than in OHCA, and in the case of the monitored patients it may be 1-2 minutes [13]. These data indicate that SCA patients during hospitalization are more optimal candidates for ECPR. Early SCA diagnosis, short no-flow times, and easy access to a specialized team and equipment may be associated with good survival rates after IHCA.

\section{Aim}

The aim of this study was to analyze and evaluate the ECPR performed by physicians of various specialties in the simulated scenario of IHCA. The critical points collected on the checklist were assessed in relation to the proposed ECPR for IHCA procedure (Figure 1).

\section{MATERIAL AND METHODS Simulation mannequin}

The SimMan 3G mannequin (Laerdal Medical, Stavanger, Norway) was used for the implementation of the high-fidelity scenario with silicone tubes creating loops to simulate pressured blood vessels. [14, 15].

\section{Simulated scenario preparation}

The scenario was carried out in real time with the use of tools used to conduct advanced ALS activities and cannulation of vessels with the ECMO device. The teams implementing the scenario were physician of various specialties such as cardiology, anesthesiology, cardiac or thoracic surgery and emergency medicine - they never worked with or known each other before. Earlier, the physicians participated in a three-day training in the use of extracorporeal medical technologies in the life-threatening conditions due to acute respiratory and circulatory failure after exhausting conventional therapy. During the classes, ECMO veno-venous ( $\mathrm{V}-\mathrm{V})$, veno-arterial ( $\mathrm{V}-\mathrm{A})$ ECPR protocols were implemented with the use of dedicated equipment. The training did not concern ALS procedures. The analyzed simulation scenario was the final one, summarizing the entire training 


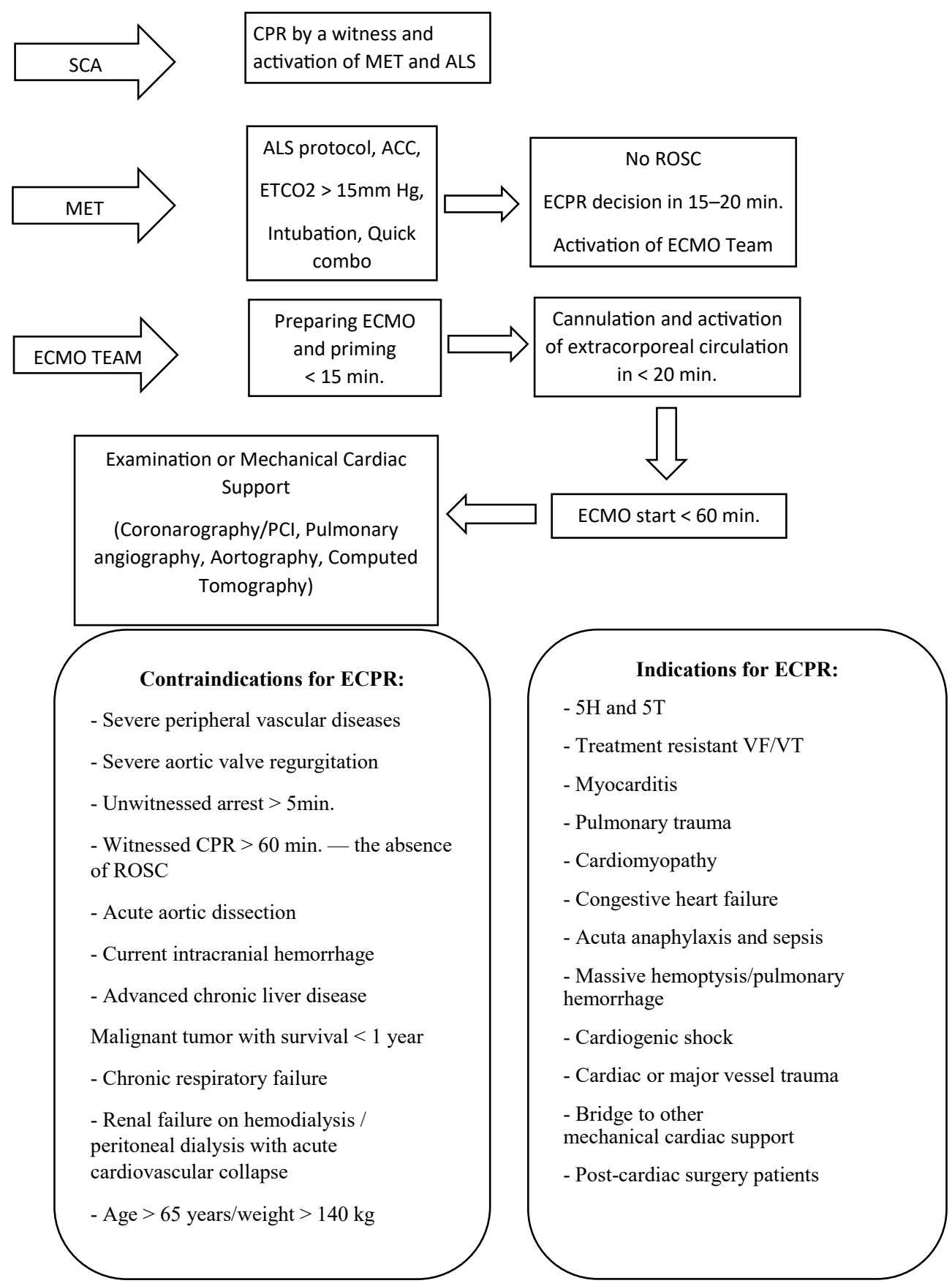

FIGURE 1. Proposed ECPR IHCA procedure

course. Before commencing the simulation, the participants were randomly divided into 3 four-member teams, regardless of the participants specialty. All study groups followed one identical scenario that was divided into three stages: I - ALS activities, $\|$ - preparation and priming of the ECMO, III - cannulation and activation of extracorporeal circulation. The scenario end time was set at 60 minutes in accordance with the assumptions adopted for the ECPR procedures. Each team individually performed its task in close cooperation with the oth- ers. Each stage of the scenario was assessed according to the previously prepared checklist (Table 1). Implementation of ALS was assessed in accordance with the adopted algorithm for defibrillating rhythms according to 2015 valid guidelines of ERC (European Resuscitation Council).

\section{Simulation case scenario}

In the scenario, SCA occurred in a 52-year-old male in the emergency room. While driving with his son, the father felt unwell and experienced shortness of 


\begin{tabular}{|c|c|c|}
\hline \multicolumn{3}{|c|}{ SCENARIO CHECKLIST } \\
\hline 1. & $\begin{array}{l}\text { Time from touching the patient to diagnosis } \\
\text { of SCA }\end{array}$ & Time \\
\hline 2. & $\begin{array}{l}\text { Initial rhythm recognition - time to first } \\
\text { shock }\end{array}$ & Time \\
\hline 3. & Advanced airway management & $+/-$ \\
\hline 4. & $\begin{array}{l}\text { Maintaining high-quality chest compression } \\
\text { and ventilation }\end{array}$ & $+/-$ \\
\hline 5. & $\begin{array}{l}\text { Decision on drug therapy ( } 1 \text { dose of } \\
\text { adrenaline and } 1 \text { dose of amiodarone) }\end{array}$ & $+/-$ \\
\hline 6. & Quick Combo decision & $+/-$ \\
\hline 7. & Time of use of ACC & Time \\
\hline 8. & Analysis Time of each CPR cycle & Time \\
\hline 9. & $\begin{array}{l}\text { Decision on qualification for ECPR and ECMO } \\
\text { therapy }\end{array}$ & $+/-$ \\
\hline 10. & Intubation time & $+/-$ \\
\hline 11. & ETCO2 monitoring & $+/-$ \\
\hline 12. & $\begin{array}{l}\text { Taking into account the reversible causes of } \\
\mathrm{H} \text { and } \mathrm{T}\end{array}$ & $+/-$ \\
\hline 13. & Assessment during resuscitation & $+/-$ \\
\hline 14. & Priming - total filling time & Time \\
\hline 15. & $\begin{array}{l}\text { Time of puncture of blood vessels from the } \\
\text { femoral access; Cannula I, Cannula II }\end{array}$ & Time \\
\hline 16. & $\begin{array}{l}\text { Time to introduce the arterial and venous } \\
\text { cannula }\end{array}$ & Time \\
\hline 17. & Removal of clamps & Time \\
\hline 18. & Time to start ECMO & Time \\
\hline 19. & Time to stop ACC & Time \\
\hline
\end{tabular}

breath and pain in his chest. This prompted the decision to drive to the hospital. During medical interview, the patient lost consciousness in the presence of witnesses. The Medical Emergency Team (MET) operating on the premises of the hospital was immediately activated. On arrival, the MET recognized SCA, implemented advanced ALS [including application of automatic chest compression device (ACCD)] and then informed the ECMO team. After arriving at the site, the latter one - without interrupting ALS - undertook preparations for vessel cannulation and began setting-up the device for extracorporeal circulation. The scenario end-point was the moment of starting the ECMO device and turning off the ACCD (ECMO Start/ ACCD Stop) (Table 2).

\section{Data presentation}

Due to a small number of performed scenarios $(n=5)$, the majority of continuous variables are

\begin{tabular}{|c|c|}
\hline \multicolumn{2}{|c|}{$\begin{array}{l}\text { Teams and equipment involved in the ECPR simulation } \\
\text { scenario }\end{array}$} \\
\hline \multicolumn{2}{|c|}{ Teams } \\
\hline Emergency staff & 1 \\
\hline MET & 4 \\
\hline Perfusion ECMO Teams & 4 (cannulation), 4 (priming) \\
\hline \multicolumn{2}{|c|}{ Equipment } \\
\hline \multicolumn{2}{|c|}{$\begin{array}{l}\text { SimMan patient simulator (Laerdal Medical, Stavargen, } \\
\text { Norway) with the ability of generating ECG rhythms, } \\
\text { intubation, chest compression }\end{array}$} \\
\hline \multicolumn{2}{|c|}{$\begin{array}{c}\text { Handmade femoral vascular loop filled under pressure with } \\
\text { red liquids, reproducing a system of vessels and implanted } \\
\text { in the groin of the mannequin covered with subcutaneous } \\
\text { tissue and artificial skin }\end{array}$} \\
\hline \multicolumn{2}{|c|}{ Advanced airway kit } \\
\hline \multicolumn{2}{|c|}{ Cardiomonitor with electrotherapy capabilities } \\
\hline \multicolumn{2}{|c|}{$\begin{array}{l}1 \mathrm{x} \text { device for automated chest compression LUCAS (Lund } \\
\text { University Cardiac Arrest System, Physio-Control Inc./Jolife } \\
\qquad \text { AB, Lund, Sweden) }\end{array}$} \\
\hline \multicolumn{2}{|c|}{ Set of oxygenator and drains system } \\
\hline \multicolumn{2}{|c|}{ Surgical set-up in the operating room for cannulation } \\
\hline ECMO - CARDIOHELP & $\begin{array}{l}\text { eater-cooler (Maquet, Rastatt, } \\
\text { any) }\end{array}$ \\
\hline
\end{tabular}

presented as medians with range (minimal-maximal values) as they do not meet criteria of normal distribution. The only exceptions were some parameters of chest compression such as depth and rate that are presented as the means with standard deviations (SD). In a consequence of limited data, we did not to perform any statistical analysis to compare any data or to find any association between teams' composition (with respect to medical specialty) and results (i.e., quality of ALS actions, times of crucial points' completion, complications/mistakes).

\section{RESULTS}

Five ECPR for IHCA high-fidelity scenarios were carried out between October 2019 and October 2020.

\section{Basic life support actions}

The analysis showed that the median (range) time from the diagnosis of SCA to the final conclusion of the patient's initial rhythm was 31 seconds (range 9-50). It resulted in a significant extension of the time to the first shock where the median was 40 sec- 
onds (range 6-91). Only in one case was it within the recommended period of time.

The mean depth of chest compressions was $4.5 \pm 0.5 \mathrm{~cm}$ and the rate of compressions was $85 \pm 10$ per minute. Each team used ACC and decision time to this device application varied from $2 \mathrm{~min} 10 \mathrm{sec}$. to $3 \mathrm{~min} .46 \mathrm{sec}$. The time from defibrillation to the rhythm analysis ranged in individual loops from $2 \mathrm{~min}$. $1 \mathrm{sec}$. to $5 \mathrm{~min}$. All teams used Quick Combo electrodes and an $\mathrm{ETCO}_{2}$ evaluation device.

\section{Extended cardio-pulmonary resuscitation techniques}

An important element of the scenario was the decision to activate the ECMO team. Such decision was taken within the wide range from $8 \mathrm{~min} .45 \mathrm{sec}$. to $14 \mathrm{~min} .15 \mathrm{sec}$. after the beginning of cardio-pulmonary resuscitation. The teams responsible for preparing ECMO assembled the kit and primed it within $10 \mathrm{~min}$. $5 \mathrm{sec}$. to $15 \mathrm{~min}$. $30 \mathrm{sec}$. In the meantime, the other participants were involved in puncture of the vessel (femoral artery and vein) followed by insertion of the cannulas necessary for effective support. The cannulation was completed in $4 \mathrm{~min} .14 \mathrm{sec}$. to $6 \mathrm{~min}$. $10 \mathrm{sec}$. After connecting the arterial and venous cannulas, the teams activated the extracorporeal support that was considered as achievement of the end-point of simulation. All teams completed successfully complex high-fidelity simulation scenario. The time from first contact with the patient by the MET team to a valid flow of $4.5 \mathrm{~L} / \mathrm{min}$ on circuit with ECMO device in V-A configuration ranged from $33 \mathrm{~min}$. $55 \mathrm{sec}$. to $37 \mathrm{~min}$. $30 \mathrm{sec}$. Of note, this period was the shortest if team leader was obvious and decisive.

The consequence of the implemented and analyzed in details high-fidelity simulation scenario was the preparation of a ready-made matrix of the high-fidelity scenario provided by the authors (Supplementary files).

\section{DISCUSSION}

In-hospital cardiac arrest is not uncommon. For example, in the United States alone, 292,000 adult patients are treated annually for IHCA with a relatively low survival rate of approximately $20 \%-30 \%$ [16-18]. The departments with the highest number of IHCA cases are intensive care, thoracic/cardiovascular and internal surgery [18]. The time from ad- mission to hospital to the onset of IHCA was found to affect the survival rate that was markedly higher if IHCA occurred within the first 3 days than after 7 days of hospitalization [19]. The etiology of cardiac arrest also has influence on long-term survival. An analysis by Schluep et al. showed that the annual survival of cardiac-related IHCA patients was 39.3\% whereas for non-cardiac patients it was only $10.7 \%$ [3]. The effectiveness of IHCA activities may also depend on the hospital profile. Mono-profile centers, limited by the number of cardiovascular specialists, are usually characterized by a higher mortality rate.

Many hospitals have established MET teams in their facilities, whose task is to quickly response to the deteriorating condition of the patient in order to prevent the occurrence of IHCA and to improve the treatment outcomes of patients in cardiac arrest. The exemplary critical vital parameters for activating the MET team include: heart rate $>150$ or $<30$ beats per minute, respiratory rate $>35$ or $<8$ breaths per minute, systolic blood pressure $<80 \mathrm{~mm} \mathrm{Hg}$, and blood oxygen saturation $<80 \%$ [20]. The role of such teams is of paramount importance since it had been found that in some patients clinical deterioration lasted several hours before the onset of IHCA. In one report, $40.0 \%$ of patients developed at least one serious abnormality 1 hour earlier, 31.1\% at least 2 hours before cardiac arrest, and 13.4\% of patients at least 4 hours prior to IHCA [20]. In another study, in almost $80 \%$ of patients with IHCA, vital parameters had already deteriorated 8 hours before SCA [21]. To improve the functioning and effectiveness of MET teams, their interdisciplinarity with a detailed division of roles, clear communication and training based on in situ high-fidelity simulations [22] are essential. In our study, a major problem at the stage of ALS activity was the lack of compliance with the time regimen in the algorithm for dealing with SCA in a defibrillating rhythm. It extended the time from defibrillation to analysis up to 5 minutes, as well as the time for drug delivery loops. The solution of such very likely problem may be the concept of a dynamic resuscitation team, where each team member is assigned to the specific role/s, and all actions are supervised by a leader. The role of a specialized team leader is to ensure that all activities are optimally coordinated and carried out on time. During ALS, there are always 6 mandatory roles/tasks to perform, such as 1 . leader, 2. compressing chest, 3 . caring of the respiratory tract (including ventilation), 4. monitoring, 5. drugs 
Supplementary files. Proposed high-fidelity scenario for ECPR IHCA

\begin{tabular}{|c|c|c|}
\hline Main Medical Issue & \multicolumn{2}{|c|}{ Extended CPR, V-A ECMO Implantation - application of ECPR } \\
\hline Educational aims & \multicolumn{2}{|c|}{$\begin{array}{l}\text { 1. Identification of potential IHCA candidates } \\
\text { 2. Knowledge of the guidelines for ECPR and DCD } \\
\text { 3. Ability to operate ACC } \\
\text { 4. Communication skills and teamwork with other ECMO team members } \\
\text { 5. Ability of rapid venous-arterial cannulation of the patient from the peripheral-femoral approach } \\
\text { during resuscitation using the mechanical chest compression device - ACC } \\
\text { 6. Ability to rapidly prepare the ECMO device and to implant VA ECMO during CPR in a cardiac arrest } \\
\text { patient on ACC }\end{array}$} \\
\hline Brief case overview & \multicolumn{2}{|c|}{$\begin{array}{l}\text { A 52-year-old male, weight } 94 \mathrm{~kg} \text {, height } 180 \mathrm{~cm} \text {, transported to the emergency department by his } \\
\text { son. While driving, the father felt unwell and began experiencing dyspnea and chest pain. They decided } \\
\text { to go to the hospital where the patient was registered and referred for observation. While interviewing } \\
\text { and monitoring vitals was attempted, the patient lost consciousness. The paramedic who was with the } \\
\text { patient immediately called the MET team and began CPR }\end{array}$} \\
\hline $\begin{array}{l}\text { Participants in the } \\
\text { scenario }\end{array}$ & $\begin{array}{l}\text { Medical Simulation Centre (MSC) staff } \\
\text { Perfusionist, clinician, CSM employees } \\
\text { (1 mannequin operation, } 1 \text { paramedic) }\end{array}$ & $\begin{array}{l}\text { Target group - training: } \\
\text { MET team } 2-4 \text { persons } \\
\text { ECMO Team: cannulation } 2-4 \text { people, priming } 2-4 \text { people }\end{array}$ \\
\hline Location & \multicolumn{2}{|l|}{ Emergency department } \\
\hline $\begin{array}{l}\text { Mannequin } \\
\text { - clothes and props }\end{array}$ & \multicolumn{2}{|c|}{$\begin{array}{l}\text { - Mannequin dressed in shirt, pants, underwear, socks and shoes } \\
\text { - Mannequin with the possibility for intubation, monitoring, defibrillation } \\
\text { - } \text { Assembled system simulating the patient's vascular system placed (hidden) inside the mannequin } \\
\text { - } \text { with high pressure of artificial blood } \\
\text { - } \quad \text { Intubation kit, drugs, fluids } \\
\text { - } \quad \text { Defibrillator self-inflating bag } \\
\text { - } \quad \text { ACC - mechanical automated chest compression device } \\
\text { - } \quad \text { Cardiohelp pump } \\
\text { - Linear clamps - at least } 4 \\
\text { - } \quad \text { ECMO therapy kit compatible with Cardiohelp pump (head, drains, oxygenator) } \\
\text { - } 1 \text { venous cannula for femoral cannulation with introducer } \\
\text { - } 1 \text { arterial cannula for femoral cannulation with introducer }\end{array}$} \\
\hline $\begin{array}{l}\text { Preliminary } \\
\text { information for } \\
\text { students (what } \\
\text { they will see on the } \\
\text { screen before the } \\
\text { start of the scenario) }\end{array}$ & \multicolumn{2}{|c|}{$\begin{array}{l}\text { A monitored patient laying on the bed while a paramedic performs chest compressions } \\
\text { The monitored rhythm - VF }\end{array}$} \\
\hline $\begin{array}{l}\text { Initial vital signs of } \\
\text { the mannequin }\end{array}$ & \multicolumn{2}{|l|}{$\begin{array}{l}\text { BP - not measurable } \\
\text { No palpable pulse in large arteries } \\
\text { No visible chest movement } \\
\text { Cyanotic } \\
\text { Pupils wide without reacting to light }\end{array}$} \\
\hline $\begin{array}{l}\text { Initial ventilator } \\
\text { parameters }\end{array}$ & \multicolumn{2}{|l|}{ Not applicable } \\
\hline $\begin{array}{l}\text { Initial pump } \\
\text { parameters }\end{array}$ & \multicolumn{2}{|l|}{ None } \\
\hline $\begin{array}{l}\text { Initial monitor } \\
\text { parameters for the } \\
\text { measurement of } \\
\text { saturation in the } \\
\text { ECMO circuit }\end{array}$ & \multicolumn{2}{|l|}{ None } \\
\hline
\end{tabular}

managing and 6. recording/documenting. However, in case of limited availability of medical personnel, some persons must play more than one role or be responsible for more than one task [19]. 
Supplementary files. Proposed high-fidelity scenario for ECPR IHCA

\begin{tabular}{|c|c|c|}
\hline Main Medical Issue & \multicolumn{2}{|c|}{ Extended CPR, V-A ECMO Implantation - application of ECPR } \\
\hline \multirow{4}{*}{$\begin{array}{l}\text { Initial laboratory } \\
\text { values: }\end{array}$} & Arterial blood gas: & Electrolytes: \\
\hline & $\begin{array}{l}\mathrm{pH}-7.18 \\
\mathrm{pO} 2-81 \mathrm{mmHg} \\
\mathrm{pCO}-63 \mathrm{mmHg} \\
\text { Sat }-77 \%\end{array}$ & $\begin{array}{l}\mathrm{Na}-151 \mathrm{mmol} / \mathrm{l} \\
\mathrm{Ca}-1.22 \mathrm{mmol} / \mathrm{l} \\
\mathrm{Cl}-105 \mathrm{mmol} / \mathrm{l} \\
\mathrm{K}-5.1 \mathrm{mmol} / \mathrm{l}\end{array}$ \\
\hline & Metabolites: & Acid-base balance: \\
\hline & $\begin{array}{l}\mathrm{Lac}-9 \mathrm{mmol} / \mathrm{l} \\
\text { Glu }-410 \mathrm{mg} / \mathrm{dl}\end{array}$ & $\begin{array}{l}\mathrm{HCO}_{3^{-}}-16 \mathrm{mmol} / \mathrm{l} \\
\mathrm{BE}-19 \mathrm{mmo} / / \mathrm{l}\end{array}$ \\
\hline Other tests: & \multicolumn{2}{|l|}{ Not applicable } \\
\hline $\begin{array}{l}\text { Situation } \\
\text { description, } \\
\text { evolution of vital } \\
\text { parameters of } \\
\text { mannequin and } \\
\text { parameters of ECMO } \\
\text { apparatus }\end{array}$ & \multicolumn{2}{|c|}{$\begin{array}{l}\text { A } 52 \text {-year-old male, weight } 94 \mathrm{~kg} \text {, height } 180 \mathrm{~cm} \text {, transported to the emergency department by his } \\
\text { son. While driving, the father felt unwell and began experiencing dyspnea and chest pain; hence, } \\
\text { they decided to go to the hospital. The patient was registered and referred for observation. While } \\
\text { interviewing and monitoring was attempted, the patient lost consciousness. The paramedic who was } \\
\text { with the patient immediately called the MET team of which he is a member himself, and began CPR. } \\
\text { MET: } \\
\text { During this time the MET team should prepare for ALS activities. Divide roles among team members } \\
\text { to implement ALS SCA algorithm in VF. During ALS with refractory VF, the MET team should consider } \\
\text { launching the ECMO team - min. } 15 \text { minutes without ROSC. } \\
\text { The VF rhythm is maintained throughout the course of the scenario. } \\
\text { If the patient is intubated and ETCO2 is connected, the value should be: } \\
\text { - manual chest compressions, ETCO2 approx. } 10 \text { mmHg } \\
\text { - in the case of ACC ETCO2 }>15 \text { mmHg } \\
\text { ECMO TEAM: } \\
\text { PRIMING } \\
\text { - assembling, filling, preparing the ECMO device } \\
\text { CANNULATION } \\
\text { - selection and preparation of equipment for the appropriate cannulation method including } \\
\text { preparation of equipment and drugs for ECMO implantation } \\
\text { preservation of sterility }\end{array}$} \\
\hline $\begin{array}{l}\text { Scenario ending } \\
\text { versions }\end{array}$ & \multicolumn{2}{|c|}{$\begin{array}{l}\text { 1. POSITIVE ENDING: } \\
\text { Proper ALS carried out in accordance with ERC/AHA, using ETCO2, ACC } \\
\text { During ALS, the MET team encountering resistant VF makes the decision within 15-20 minutes to } \\
\text { activate the ECMO team } \\
\text { ECMO Team: } \\
\text { Correctly prepares and primes ECMO device within } 15 \text { minutes } \\
\text { Chooses the femoral cannulation method as the fastest access to VA ECMO implantation, prepares } \\
\text { the appropriate cannula (femoral vein and femoral artery) and drugs for implantation (heparin, local } \\
\text { lidocaine - arterial spasm) within } 20 \text { minutes } \\
\text { If, from SCA through ALS, the initiation of the VA ECMO procedure, including cannulation of vessels, } \\
\text { preparation of the ECMO apparatus, connection with cannulas and starting the VA ECMO within } 60 \\
\text { minutes - the scenario ends positively } \\
\text { 2. NEGATIVE ENDING } \\
\text { If, from SCA through ALS, VA ECMO initiation, vessel cannulation, ECMO apparatus preparation, } \\
\text { connection with cannulas and start of VA ECMO is longer than } 60 \text { minutes - the scenario ends } \\
\text { negatively } \\
\text { 3. Consider the DCD protocol } \\
\text { 4. Conduct CPR with ETCO2, ACC }\end{array}$} \\
\hline
\end{tabular}

In-hospital cardiac arrest differs significantly from OHCA in term of both patient population and availability of new technologies [23]. Patients with IHCA are usually worse candidates for CPR/ECPR than OHCA patients. It was found that initial defibrillation rhythm among IHCA individuals was diagnosed more rarely than in those with OHCA (38\% vs. 59\%). If SCA occurs in hospital wards, it is highly possible that monitoring devices will be used, starting with $\mathrm{ETCO}_{2}$, through cardiomonitors, and ending with peripheral arterial and central venous catheters [24]. The use of the latter ones makes it possible to control cardiac output and index, the parameters that can predict early ROSC [24]. In the recent years, the availability of bedside echo- 


\begin{tabular}{|c|c|}
\hline Indications for ECPR & Contraindications for ECPR \\
\hline Reversible causes of SCA: coronary artery obstruction, pulmonary embolism & Severe peripheral vascular disease \\
\hline VFNT refractory to treatment & Severe aortic valve regurgitation \\
\hline Myocarditis & Unwitnessed arrest $>5 \mathrm{~min}$ \\
\hline Pulmonary trauma & Witnessed CPR $>60$ min. - the absence of ROSC \\
\hline Cardiomyopathy & Acute aortic dissection \\
\hline Congestive heart failure & Current intracranial hemorrhage \\
\hline Acute anaphylaxis & Advanced chronic liver disease \\
\hline Massive hemoptysis/pulmonary hemorrhage & Active malignancy with estimated survival $<1$ year \\
\hline Poisoning & Chronic respiratory failure \\
\hline Sepsis & $\begin{array}{l}\text { End-stage renal disease on hemodialysis or } \\
\text { peritoneal dialysis with acute cardiovascular collapse }\end{array}$ \\
\hline Cardiogenic shock & age $>75$ year \\
\hline Cardiac or major vessel trauma & weight $>140 \mathrm{~kg}$ \\
\hline \multicolumn{2}{|l|}{ ECMO Site } \\
\hline Bridge to another extracorporeal left ventricular assist device & Mobile team \\
\hline Patients before or after cardiac surgery (transplant) & Cardiac surgery intensive care units \\
\hline \multirow[t]{3}{*}{ Patients before or after cardiac surgery } & Heart catheterization laboratory \\
\hline & Cardiac surgery intensive care units \\
\hline & Operating theatre \\
\hline
\end{tabular}

\begin{tabular}{|c|c|c|}
\hline Stage of ECPR & Problems/comments & Countermeasures \\
\hline \multirow[t]{6}{*}{ ALS } & Late identification of the initial rhythm & $\begin{array}{l}\text { Assessment of vital signs while assessing the rhythm on the } \\
\text { monitor }\end{array}$ \\
\hline & Delay in delivery of first shock & $\begin{array}{l}\text { Charging the defibrillator to complete the shockable rhythm } \\
\text { recognition procedure }\end{array}$ \\
\hline & $\begin{array}{l}\text { Instrumental opening of the airways } \\
\text { (intubation) - no confirmation }\end{array}$ & $\begin{array}{l}\text { Auscultation of the chest as the end of the intubation } \\
\text { procedure }\end{array}$ \\
\hline & $\begin{array}{l}\text { Relatively poor quality of chest } \\
\text { compressions and ventilation }\end{array}$ & $\begin{array}{l}\text { BLS training, periodically repeated with the use of quality } \\
\text { control mannequins }\end{array}$ \\
\hline & $\begin{array}{l}\text { Extended length of time to run ACC } \\
\text { device }\end{array}$ & $\begin{array}{l}\text { Training for doctors of various specializations on the use } \\
\text { of ACC devices }\end{array}$ \\
\hline & $\begin{array}{l}\text { Exceeding the time for resuscitation } \\
\text { loops }\end{array}$ & $\begin{array}{l}\text { Division of roles in the team, the role of the leader, role of } \\
\text { the recorder }- \text { documenting the time of individual activities }\end{array}$ \\
\hline ECPR Activation & Within 15-20 minutes & $\begin{array}{l}\text { Increasing awareness of the possibility of using the extended } \\
\text { CPR } \\
\text { When to go } \\
\text { When not to go }\end{array}$ \\
\hline $\begin{array}{l}\text { Preparing the device for } \\
\text { extracorporeal circulation }\end{array}$ & $\begin{array}{l}\text { Difficulty assembling the } \\
\text { extracorporeal perfusion device }\end{array}$ & Practical and manual training \\
\hline Priming & $\begin{array}{l}\text { Assessed: } \\
\text { - preparation time } \\
\text { - completeness of the apparatus } \\
\text { Maximum priming time of } 15 \text { minutes }\end{array}$ & Practical and manual training: early filling of the device \\
\hline $\begin{array}{l}\text { Cannulation and } \\
\text { activating extracorporeal } \\
\text { circulation }\end{array}$ & $\begin{array}{l}\text { Maintaining asepsis } \\
\text { Heparin administration, } \\
\text { Maximum time of } 20 \text { minutes }\end{array}$ & Practical and manual training \\
\hline
\end{tabular}


cardiography that can be used during cardiac arrest has also increased. It enables detection of reversible causes of SCA (cardiac tamponade) or identification of spontaneous movements of the heart muscle [25].

In some cases, if conventional CPR techniques are ineffective, ECPR may be a solution. In recent years and months (SARS-CoV-2 pandemic), the availability of ECMO devices in hospitals has increased significantly. The findings in the previous publications favor ECPR in terms of mortality over conventional CPR $[26,27]$. Wang et al. showed survival to hospital discharge at the level over 30\% [28]. A Brussels study revealed favorable neurological outcomes at 3 months, in $21 \%$ of SCA patients following ECPR vs. only $11 \%$ after conventional CPR. The long-term survival data after SCA also favors ECPR over conventional CPR [29]. ECPR activation seems to be more efficient in IHCA than in OHCA. Previous report stressed that availability of equipment and the ECMO team in hospitals enables earlier initiation of extracorporeal support in IHCA than OHCA conditions [11].

Without any doubts, ECPR is a complex procedure and multidisciplinary team must be involved. It is a safe and clinically relevant method if it is applied within appropriate time. A fast decision to start the ECPR procedure is of crucial importance. According to the recommendations, it should be activated in the absence of ROSC within 15 minutes from SCA occurrence. In our study all teams managed to initiate ECPR within recommended period of time. Of note, low-flow time (defined as between start of CPR to ECPR activation) strongly correlates with survival, and probability of hospital discharge is higher when a shorter CPR duration [29, 30]. Kim et al. showed that every 10-minute increase in the duration of lowflow increases mortality by $5 \%[5,31]$. Moreover, it was proven previously that ECPR is effective in reversible SCA if activated within 60 minutes. All our teams in the simulated scenario were able to connect mannequins to ECMO device in less than 40 minutes after SCA, which should be considered as perfect result. Of note, all physicians involved in ECPR were soon after ECMO course with simulation as a crucial form of education method to gain experience in extraordinary complex and sophisticated medical technology. Although it was not a subject of our study, it should be mentioned that age of ECPR candidates matters. Hirlekar et al. demonstrated in their study that the 30-day survival rate decreased dramatically with each decade over 70 years of life [32]. Therefore, ECPR is indicated for a selected group of SCA patients. However, there are no specific criteria for indications and methods of patient selection, and consequently they may different depending on the hospital [31] (Table 3).

\section{Limitation}

The major limitation of our study is a relatively small number of scenarios. Due to obvious pandemic restrictions only five scenarios were implemented as a pilot study. The authors plan to complete between 15 to 20 scenarios in total. Thus, in a title of our study we did point that it was an initial experience. Although, center for medical simulation is very useful for achieving practical skills it does not reflect completely natural circumstances, particularly in emergent situations. The idealized conditions of IHCA are associated with the availability of an interdisciplinary MET, constant readiness of the team and equipment, proper organization and constant preparation of the device for extracorporeal circulation (Table 4). This fact could have impacted on perfect results of examined teams, in terms of time to make a decision to connect ECMO (low-flow one) and to ECPR activation.

\section{CONCLUSIONS}

Implementation of ECPR procedure is possible within recommended time after IHCA. In order to improve the survival rate of SCA patients, regular training for medical personnel is necessary. This should include BLS/ALS, extracorporeal perfusion setup and cannulation skills. It has also been shown that training with application of high-fidelity simulation techniques is of paramount importance for achieving and maintaining ECPR skills, not only manual but also in effective communication.

\section{ABBREVIATIONS}

IHCA - in-hospital cardiac arrest

OHCA — out-of-hospital cardiac arrest

CPR - cardiopulmonary resuscitation

ECPR - extended cardiopulmonary resuscitation

ALS - advanced life support

ECMO - extracorporeal membrane oxygenation

SCA — sudden cardiac arrest

ROSC — return of spontaneous circulation

MET - medical emergency teams

ETCO2 - end tidal carbon dioxide

ACC - automated chest compression

DCD - donation after circulatory death

BLS - basic life support 


\section{REFERENCES}

1. Sandroni C, Nolan J, Cavallaro F, et al. In-hospital cardiac arrest: incidence, prognosis and possible measures to improve survival. Intensive Care Med. 2007; 33(2): 237-245, doi: 10.1007/s00134-006-0326-z, indexed in Pubmed: 17019558.

2. Yilmaz $\mathrm{S}, 0$ murlu I. Survival after cardiopulmonary arrest in a tertiary care hospital in Turkey. Annals of Saudi Medicine. 2019; 39(2): 92-99, doi: 10.5144/0256-4947.2019.07.03.1400.

3. Schluep M, Gravesteijn BY, Stolker RJ, et al. One-year survival after in-hospital cardiac arrest: A systematic review and meta-analysis. Resuscitation. 2018; 132: 90-100, doi: 10.1016/j.resuscitation.2018.09.001, indexed in Pubmed: 30213495.

4. Girotra S, Nallamothu BK, Spertus JA, et al. American Heart Association Get with the Guidelines-Resuscitation Investigators. Trends in survival after in-hospital cardiac arrest. N Engl J Med. 2012; 367(20): 19121920, doi: 10.1056/NEJMoa1109148, indexed in Pubmed: 23150959.

5. Kim YS, Lee YJ, Won KiB, et al. Extracorporeal Cardiopulmonary Resuscitation with Therapeutic Hypothermia for Prolonged Refractory In-hospital Cardiac Arrest. Korean Circ J. 2017; 47(6): 939-948, doi: 10.4070/kcj.2017.0079, indexed in Pubmed: 29171213.

6. Virdi G, Picton S, Fothergill R. London Ambulance Service NHS Trust Cardiac Arrest Annual Report. 2014; 15: 2015.

7. Monsieurs KG, Nolan JP, Bossaert LL, et al. ERC Guidelines 2015 Writing Group. European Resuscitation Council Guidelines for Resuscitation 2015: Section 1. Executive summary. Resuscitation. 2015; 95: 1-80, doi: 10.1016/j.resuscitation.2015.07.038, indexed in Pubmed: 26477410.

8. Sip M, Puslecki M, Dabrowski $M$, et al. Extended cardiopulmonary resuscitation: from high fidelity simulation scenario to the first clinical applications in Poznan out-of-hospital cardiac arrest program. Perfusion. 2020 [Epub ahead of print]: 267659120981811, doi: 10.1177/0267659120981811, indexed in Pubmed: 33325325.

9. Czekajlo $M$, Dabrowski M, Puslecki $M$, et al. Using ECMO VV in the COVID-19 pandemic. Disaster and Emergency Medicine Journal. 2020, doi: 10.5603/demj.a2020.0022.

10. Smereka J, Puslecki $M$, Ruetzler $K$, et al. Extracorporeal membrane oxygenation in COVID-19. Cardiol J. 2020; 27(2): 216-217, doi: 10.5603/CJ.a2020.0053, indexed in Pubmed: 32285929.

11. Duerschmied D, Zotzmann V, Rieder $M$, et al. Myocardial infarction type 1 is frequent in refractory out-of-hospital cardiac arrest (OHCA) treated with extracorporeal cardiopulmonary resuscitation (ECPR). Sci Rep. 2020; 10(1): 8423, doi: 10.1038/s41598-020-65498-9, indexed in Pubmed: 32440003.

12. Witten L, Gardner R, Holmberg MJ, et al. Reasons for death in patients successfully resuscitated from out-of-hospital and in-hospital cardiac arrest. Resuscitation. 2019; 136: 93-99, doi: 10.1016/j.resuscitation.2019.01.031, indexed in Pubmed: 30710595.

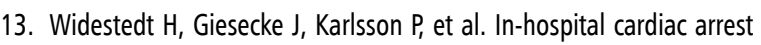
resuscitation performed by the hospital emergency team: A 6-year retrospective register analysis at Danderyd University Hospital, Sweden. F1000Res. 2018; 7: 1013, doi: 10.12688/f1000research.15373.1, indexed in Pubmed: 30356455.
14. Puślecki $M$, Ligowski $M$, Kiel $M$, et al. ECMO therapy simulator for extracorporeal life support. Am J Emerg Med. 2018; 36(3): 506-508, doi: 10.1016/j.ajem.2017.07.082, indexed in Pubmed: 28780233.

15. Puslecki M, Ligowski $M$, Kiel $M$, et al. Prototype of extracorporeal membrane oxygenation (ECMO) therapy simulator used in regional ECMO program. J Thorac Dis. 2018; 10(8): 5073-5079, doi: 10.21037/ jtd.2018.07.25, indexed in Pubmed: 30233882.

16. Merchant RM, Yang L, Becker LB, et al. American Heart Association Get With The Guidelines-Resuscitation Investigators. Incidence of treated cardiac arrest in hospitalized patients in the United States. Crit Care Med. 2011; 39(11): 2401-2406, doi: 10.1097/ CCM.0b013e3182257459, indexed in Pubmed: 21705896.

17. Girotra S, Nallamothu BK, Spertus JA, et al. American Heart Association Get with the Guidelines-Resuscitation Investigators. Trends in survival after in-hospital cardiac arrest. N Engl J Med. 2012; 367(20): 19121920, doi: 10.1056/NEJMoa1109148, indexed in Pubmed: 23150959.

18. Riley LE, Mehta HJ, Lascano J. Single-center In-hospital Cardiac Arrest Outcomes. Indian J Crit Care Med. 2020; 24(1): 44-48, doi: 10.5005/ jp-journals-10071-23327, indexed in Pubmed: 32148348.

19. Qazi AH, Kennedy K, Bradley SM, et al. American Heart Association Get With the Guidelines Resuscitation Investigators. Impact of timing of cardiac arrest during hospitalization on survival outcomes and subsequent length of stay. Resuscitation. 2017; 121: 117-122, doi: 10.1016/j.resuscitation.2017.10.003, indexed in Pubmed: 29031624.

20. Chan ML, Spertus JA, Tang F, et al. Missed opportunities in use of medical emergency teams prior to in-hospital cardiac arrest. Am Heart J. 2016; 177: 87-95, doi: 10.1016/j.ahj.2016.04.014, indexed in Pubmed: 27297853.

21. American Heart Association Life Support Algorithms. Bone Marrow Transplantation. 1998: 616-621, doi: 10.1201/9781498712903-29.

22. Nallamothu BK, Guetterman TC, Harrod M, et al. How Do Resuscitation Teams at Top-Performing Hospitals for In-Hospital Cardiac Arrest Succeed? A Qualitative Study. Circulation. 2018; 138(2): 154-163, doi: 10.1161/ CIRCULATIONAHA.118.033674, indexed in Pubmed: 29986959.

23. Moskowitz A, Holmberg MJ, Donnino MW, et al. In-hospital cardiac arrest: are we overlooking a key distinction? Curr Opin Crit Care. 2018; 24(3): 151-157, doi: 10.1097/MCC.0000000000000505, indexed in Pubmed: 29688939.

24. Gershengorn $H B$, Garland $A$, Kramer $A$, et al. Variation of arterial and central venous catheter use in United States intensive care units. Anesthesiology. 2014; 120(3): 650-664, doi: 10.1097/ ALN.0000000000000008, indexed in Pubmed: 24424071.

25. Gaspari R, Weekes A, Adhikari S, et al. et al.. A retrospective study of pulseless electrical activity, bedside ultrasound identifies interventions during resuscita-tion associated with improved survival to hospital admission. A REASON Study Resuscitation. 2017; 120: 103-7.

26. Chen YS, Lin JW, Yu HY, et al. Cardiopulmonary resuscitation with assisted extracorporeal life-support versus conventional cardiopulmonary resuscitation in adults with in-hospital cardiac arrest: an observational study and propensity analysis. Lancet. 2008; 372(9638): 554-561, doi: 10.1016/S0140-6736(08)60958-7, indexed in Pubmed: 18603291. 
27. Ahn C, Kim W, Cho Y, et al. Efficacy of extracorporeal cardiopulmonary resuscitation compared to conventional cardiopulmonary resuscitation for adult cardiac arrest patients: a systematic review and meta-analysis. Sci Rep. 2016; 6: 34208, doi: 10.1038/srep34208, indexed in Pubmed: 27659306.

28. Wang $\mathrm{CH}$, Chou NK, Becker LB, et al. Improved outcome of extracorporeal cardiopulmonary resuscitation for out-of-hospital cardiac arrest--a comparison with that for extracorporeal rescue for in-hospital cardiac arrest. Resuscitation. 2014; 85(9): 1219-1224, doi: 10.1016/j. resuscitation.2014.06.022, indexed in Pubmed: 24992872.

29. Patricio D, Peluso L, Brasseur A, et al. Comparison of extracorporeal and conventional cardiopulmonary resuscitation: a retrospective pro- pensity score matched study. Crit Care. 2019; 23(1): 27, doi: 10.1186/ s13054-019-2320-1, indexed in Pubmed: 30691512.

30. Lang CN, Schroth F, Zotzmann V, et al. Good long term quality of life after emergency extracorporeal life support for cardiogenic shock and extracorporeal cardiopulmonary resuscitation. Resuscitation. 2019; 143: 66-67, doi: 10.1016/j.resuscitation.2019.08.003, indexed in Pubmed: 31401138.

31. Kim H, Cho YH. Role of extracorporeal cardiopulmonary resuscitation in adults. Acute Crit Care. 2020; 35(1): 1-9, doi: 10.4266/ acc.2020.00080, indexed in Pubmed: 32131575.

32. Hirlekar G, Karlsson T, Aune S, et al. Survival and neurological outcome in the elderly after in-hospital cardiac arrest. Resuscitation. 2017; 118: 101-106, doi: 10.1016/.jesuscitation.2017.07.013, indexed in Pubmed: 28736324. 